\title{
Backstabbing swordfish: a rare cause of traumatic hemiparesis
}

\author{
Prabu Rau Sriram, MD, ${ }^{1}$ Timothy Cheng Tsin Jien, MBBS, ${ }^{2}$ and \\ Pulivendhan Sellamuthu, MBBS, FRCS(SN) ${ }^{1}$
}

1Department of Neurosurgery, Queen Elizabeth Hospital, Kota Kinabalu; and 'Department of Orthopaedics, Lahad Datu Hospital, Lahad Datu, Sabah, Malaysia

\begin{abstract}
Swordfish attacks on humans are uncommon, with only a few case reports available in the current literature. The authors report the first known case of a penetrating spinal injury from a swordfish, in which the patient presented with a small stab wound and hemiparesis. The presentation of a fisherman with hemiparesis and a harmless-looking stab wound must alert clinicians to the possibility of penetrating swordfish injuries to the spine.

https://thejns.org/doi/abs/10.3171/2016.12.SPINE16586
\end{abstract}

KEY WORDS swordfish; penetrating spinal injury; traumatic hemiparesis; CSF leak; spinal cord injury; trauma

$\mathrm{S}$ WORDFISH are known for the prolongation of their bill or upper jaw that looks like a sword, hence the name. ${ }^{1}$ They commonly attack only upon provocation; thus, among the victims of swordfish attacks, the majority are fishermen. To our knowledge, only 1 case of an unprovoked swordfish attack has been reported. ${ }^{2}$ In the patient in this report, the swordfish bill penetrated deep (about $4 \mathrm{~cm}$ ) into his cervical spine, causing CSF leakage and immediate hemiparesis. The management of this patient, however, follows the general management of patients with penetrating spinal injuries.

\section{Case Report}

History and Examination

A 55-year-old fisherman was fishing when he was hit by an unknown object at the back of his neck while he was in the water. The patient experienced sharp pain and developed instant weakness of his right upper and lower limbs. Due to logistical and transportation issues, he was not brought to the hospital until 12 hours after the trauma.

On admission to the emergency department, his Glasgow Coma Scale score was 15, with no airway, breathing, or circulation compromise. Examination of his neck revealed a tiny puncture wound with clear fluid dripping from it (Fig. 1). No active bleeding was noted and he had no other wounds. A neurological examination revealed a syndrome similar to Brown-Séquard, with right hemiparesis, $0 / 5$ power in all upper and lower limb myotomes, and loss of sensation for light touch from C-5 downward. However, pain and temperature sensation were intact. Thus, the neurological examination revealed involvement of the right corticospinal tract and posterior spinal column. His anal tone was present. A cervical collar was applied immediately.

Computed tomography of the cervical spine revealed a bone-dense object resembling a fish bill in the right posterior paravertebral soft tissue at the level of C-2 with associated soft-tissue edema. Bone fragments were noted in the C1-2 interspinous space and also within the spinal cord at the level of C-2. No cervical fractures were noted. Figure 2 shows a plain radiograph and sagittal CT scan of the patient showing the object.

\section{Operation and Postoperative Course}

The patient was then referred to the neurosurgical unit for spinal exploration. A partial laminectomy and removal of the fish bill were performed. Both upper and lower jaws of the fish bill were found to have been embedded in the interspinous muscle and ligaments of $\mathrm{C} 1-2$ vertebrae. CSF was leaking from the dural tear. Both of the swordfish jaws were removed cautiously and the dura was repaired with fascia and tissue sealant. All fragments were completely removed (Fig. 3). 


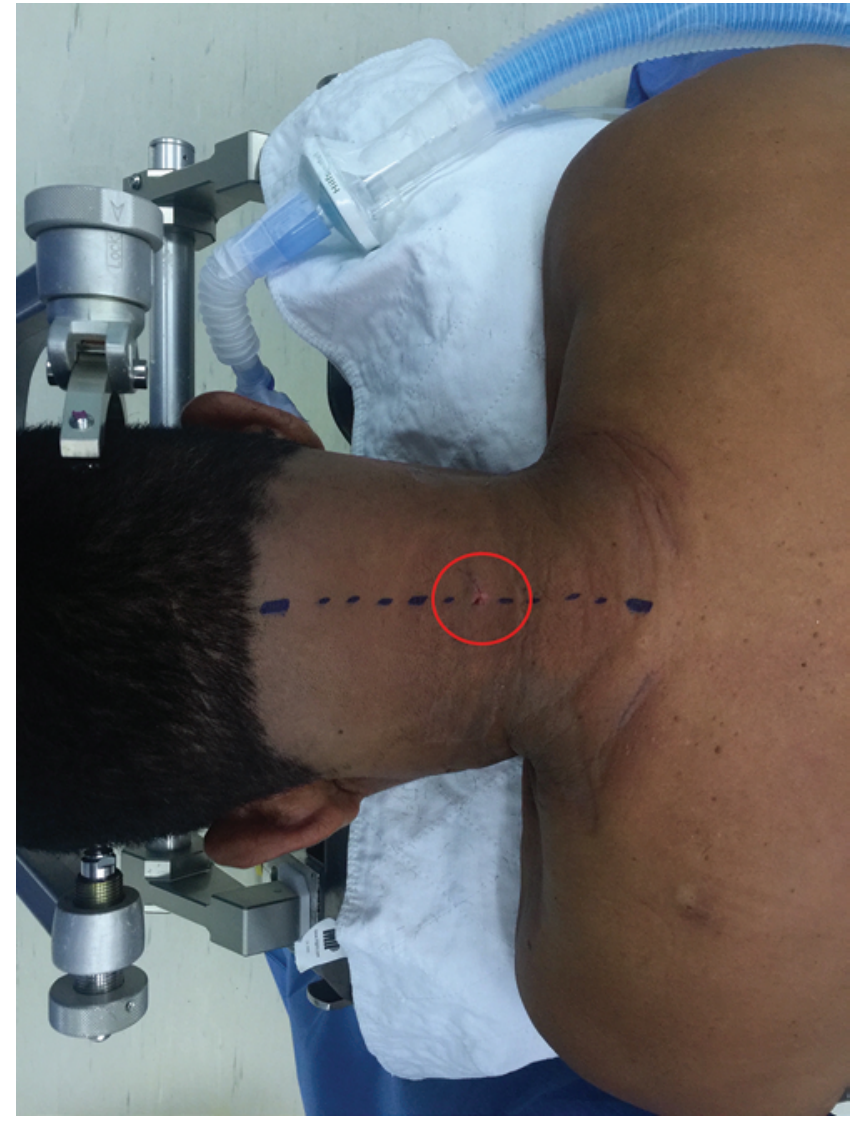

FIG. 1. Photograph of the patient illustrating the tiny entry point of the swordfish bill over the posterior cervical region (circle), which could easily be missed without a thorough examination. Figure is available in color online only.

Postoperatively, 1 week later, the patient's upper and lower limb myotomes regained power (2/5). Physical rehabilitation has been planned to help him regain function and independence in activities of daily living.

\section{Discussion}

Penetrating injuries contribute to almost $25 \%$ of all spinal cord injuries. Of these injuries, the thoracic spine is the most commonly affected (52\%) followed by the cervical spine (14\%). Most of the reported penetrating spinal cord injuries are the result of missile injury or gunshot wounds, ${ }^{5}$ with very few caused by animals.

There are a scarce number of news articles reporting fishermen deaths due to swordfish attacks. Swordfish are a known threat to fishermen, especially in midwaters (20$60 \mathrm{~m}$ ), and commonly attack after being provoked. ${ }^{2,3}$ However, only 5 cases of penetrating injury from a swordfish have been reported in the medical literature and none of those involved the cervical spine. Among the 5, only 1 was an unprovoked attack by a swordfish, which caused a penetrating injury to the vertebral column via the abdomen. ${ }^{2}$

Swordfish, known as Xiphias Gladius or broadbill, are midwater fish that attained their name mainly due to the long sword-like extension of their upper jaw. Swordfish are found in oceanic regions worldwide. This sword-like bill,
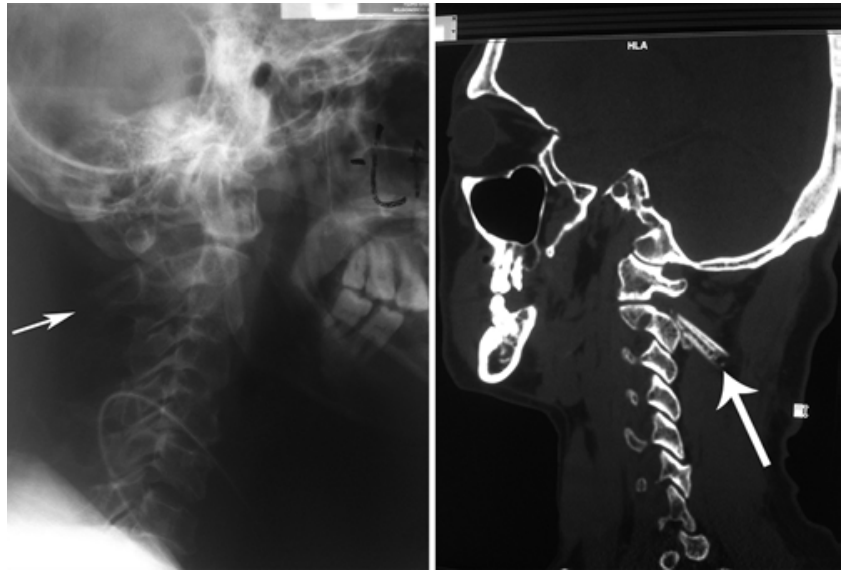

FIG. 2. Lateral view of cervical radiograph (left) and sagittal CT scan in the bone setting (right). The swordfish bill, which penetrated deep into the cervical spine, is indicated by an arrow at the level of C-2. Surrounding soft-tissue edema is noted as well.

however, is not used to spear but to slash their predators and prey. The maximum-recorded weight for a swordfish is $650 \mathrm{~kg}$ and they can reach a maximum length of $455 \mathrm{~cm}$. However, the common length achieved is 3 meters. They are commonly observed on the surface of waters. Known as one of the fastest fish, its speed and agility make it a deadly predator. ${ }^{1}$ The velocity of the fish, combined with the long and sharp pointed bill, contributed to the 4-cmdeep penetration in our patient, reaching into the spinal cord.

Our patient presented with a small, harmless-looking wound measuring $1 \mathrm{~cm}$ (Fig. 1) with clear fluid discharge. The plain radiograph did not reveal any obvious foreign body, thus a CT scan was performed (Fig. 2). Decompression was performed early to increase the chances of neurological improvement.

Needlefish and stingrays are among the other sea creatures that have been reported to cause penetrating injuries
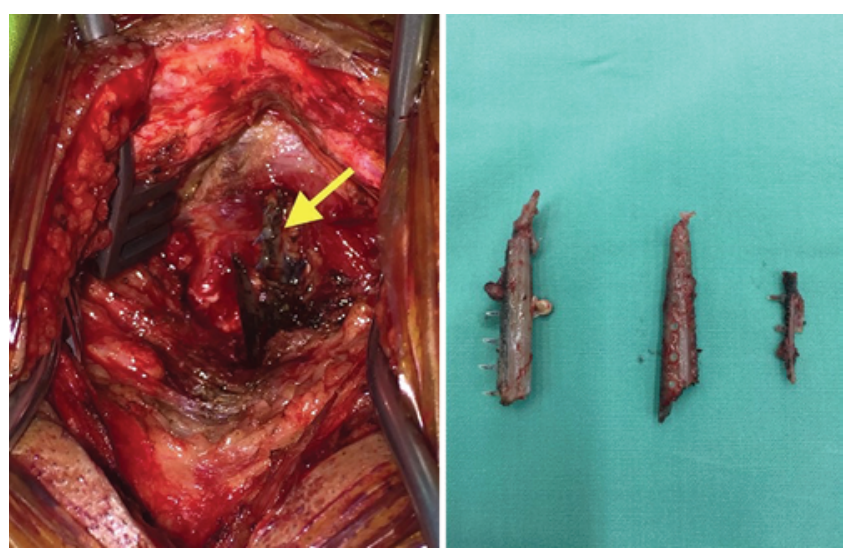

FIG. 3. Intraoperative image (left) after dissection of paravertebral muscles shows the swordfish bill (arrow) that penetrated into the cervical spine and stuck to it. Sharp pointed projections along the swordfish bill can be observed. All fragments of the swordfish bill were removed from the patient (right). This particular swordfish was young and still had its teeth. Figure is available in color online only. 
to the head and spine ${ }^{4,6}$ Groen et al. reported a penetrating spine injury at the thoracic level from a stingray spine, but it was an alleged assault during a fight. ${ }^{4}$ In particular, organic penetrating material to the spine is rarely observed in real life or in the literature. However, an organic foreign-body penetrating injury is associated with a higher risk of infection and some have advocated a longer duration of antibiotics in these cases. This is due to the nature of the organic material or its remnants, which are liable to decay inside the body. Removal of the object in such cases is crucial. $2,7,8$

The management of a penetrating cervical cord injury due to a swordfish bill follows the general principles of a penetrating spinal cord injury. As such, the foreign material, which in this case was the bill of a swordfish, has to be removed. Decompressive laminectomy in these patients has been controversial, especially in improving neurological function. Klimo et al. has reviewed both military and civilian penetrating spinal injury and concluded surgery may or may not have a role. ${ }^{5}$ The ambiguity of the role of surgery is still present as concluded by the review. The presence of a dural tear with CSF leakage, however, is a strong indication for dural repair to prevent complications from this leakage.

A penetrating swordfish injury to the spine is very rare and is a potential threat that fishermen should be aware of. A high index of clinical suspicion is needed when approaching fishermen or swimmers who present with neurological deficit and a harmless-looking wound over the spine. Prompt CT or MRI must be performed because plain radiographs are unreliable in detecting fish bills.

\section{References}

1. Gardieff S: Ichthyology. Swordfish, Xiphias gladius. Florida Museum of Natural History. (https://www.flmnh.ufl.edu/ fish/discover/species-profiles/xiphias-gladius) [Accessed February 14, 2017]

2. Georgiadou D, Zografos GN, Vaidakis D, Avlonitis S, Katopodi A, Tzirakis EN, et al: Swordfish bill injury involving abdomen and vertebral column: case report and review. BMC Surg 10:30, 2010

3. Gooi BH, Khamizar W, Suhani MN: Swordfish attack-death by penetrating head injury. Asian J Surg 30:158-159, 2007

4. Groen RJ, Kafiluddin EA, Hamburger HL, Veldhuizen EJ: Spinal cord injury with a stingray spine. Acta Neurochir (Wien) 144:507-508, 2002

5. Klimo P Jr, Ragel BT, Rosner M, Gluf W, McCafferty R: Can surgery improve neurological function in penetrating spinal injury? A review of the military and civilian literature and treatment recommendations for military neurosurgeons. Neurosurg Focus 28(5):E4, 2010

6. McCabe MJ, Hammon WM, Halstead BW, Newton TH: A fatal brain injury caused by a needlefish. Neuroradiology 15:137-139, 1978

7. Mendonça-Caridad JJ, Juiz Lopez P, Francos L, Rodriguez M: Swordfish bill injury involving the pterygomaxillary fossae: surgical management and case report. J Oral Maxillofac Surg 66:1739-1743, 2008

8. Potapov AA, Okhlopkov VA, Latyshev YA, Serova NK, Eolchiyan SA: Penetrating skull and brain injuries caused by non-metallic foreign bodies (literature review over the past 50 years). Zh Vopr Neirokhir Im N N Burdenko 6:87-92, 2014

\section{Disclosures}

The authors report no conflict of interest concerning the materials or methods used in this study or the findings specified in this paper.

\section{Author Contributions}

Conception and design: Sriram, Tsin Jien. Acquisition of data: Sriram, Tsin Jien. Analysis and interpretation of data: Sriram. Drafting the article: Sriram, Tsin Jien. Critically revising the article: Sriram. Reviewed submitted version of manuscript: all authors. Approved the final version of the manuscript on behalf of all authors: Sriram. Administrative/technical/material support: Sellamuthu. Study supervision: Sellamuthu.

\section{Correspondence}

Prabu Rau Sriram, 17 Lorong Austral 11, Austral Park, 88200 Kota Kinabalu, Sabah, Malaysia. email: praburau@gmail.com. 